\title{
Extreme events, climate risks and insurance
}

\author{
Christophe Courbage $^{1} \cdot$ Maryam Golnaraghi $^{2}$
}

\author{
(c) The Geneva Association 2021
}

Physical climate risks associated with extreme weather events, such as tropical cyclones, heatwaves and floods, and slow-changing conditions, such as sea level rise and prolonged higher temperatures, are increasing due to climate change. Recent figures show the past seven years are on track to be the seven warmest on record (WMO 2021), and more severe, more frequent extreme events are unfortunately becoming the new norm. The costs associated with extreme events are exacerbated further by various factors, leading to growing exposure and vulnerabilities associated with increasing concentrations of people and assets in areas of high risk linked to land use, urbanisation and development practices (IPCC 2021).

Over the last decade, efforts have been underway to build resilience to the impacts of extreme events in a changing climate. Rising socio-economic impacts have brought focus to the need for a paradigm shift towards a risk-based, anticipatory, all-of-society approach to managing the potential impacts of catastrophes (The Geneva Association 2020). Efforts have focused on improving risk management practices, including enhancing disaster risk assessment and risk communication to improve risk-informed decision-making, early warning and emergency preparedness, risk reduction and risk prevention, risk financing and transfer, and efforts to promote the need to build back better (or not build at all) after disasters.

The rising effects of weather-related events are also gaining the attention of the financial sector. This is driven by the concern that climate change could be a systemic risk to global financial stability, creating the need to enable long-term financing for a well-planned transition to a resilient low-carbon economy. The Financial Stability Board's Task Force on Climate-related Financial Disclosures provided general and sector-specific guidelines for publicly traded companies to assess and disclose their climate-related risks in their annual reports (TCFD 2017). International rating agencies recently started considering climate and disaster risk and related risk management practices in their sovereign, municipal and corporate credit ratings.

Christophe Courbage

christophe.courbage@ hesge.ch

1 Geneva School of Business Administration, University of Applied Sciences Western Switzerland (HES-SO), Geneva, Switzerland

2 The Geneva Association, Zurich, Switzerland 
As the impacts of natural hazards also increase globally, more attention has been focused on the role and value proposition of the insurance industry in driving disaster resilience (OECD 2017; Kousky 2019). This is also supported by emerging evidence that countries with widespread market-based insurance coverage tend to recover faster from the financial impacts of extreme events, and that it is the uninsured part of losses that drives macroeconomic costs (von Peter et al. 2012). This has not only generated more interest in traditional insurance products, but also spurred innovations in alternative risk transfer solutions. Furthermore, governments are increasingly realising the value of working more closely with the insurance industry in areas such as catastrophe risk modelling, climate adaptation and disaster prevention research (The Geneva Association 2018).

Yet despite these developments, much more work lies ahead to meaningfully and efficiently manage physical risks in a changing climate and enable concerted efforts that engage the public and private sectors to reduce these risks and build societal resilience. This also calls for a better understanding of the role of insurance in dealing with climate-related risks.

This thematic issue of The Geneva Papers contributes to this understanding by addressing four important issues: the awareness of insurers of climate risks and opportunities, the role of insurance in improving disaster risk preparedness, optimal public-private insurance schemes to cover natural catastrophes, and finally the use of reinsurance and CAT bonds as natural catastrophe risk transfer tools. We provide below a brief summary of the papers included in the issue.

The paper by Nadine Gatzert and Philipp Reichel studies empirically the awareness of European and U.S. insurance companies of climate-related risks and opportunities. Their results show that over the 2009-2018 period, larger European insurers are significantly more likely to exhibit such awareness. When controlling for subsectors, property \& casualty $(\mathrm{P} \& \mathrm{C})$ insurers tend to be more aware of the risks and opportunities resulting from climate change. They also find a positive impact of climate risk awareness on firm value. Their findings provide practical relevance for insurers, given that climate-related public and regulatory pressure will likely continue to intensify in the future.

The paper by Peter Robinson and Wouter Botzen investigates the role of insurance in promoting behavioural changes. They address the effect of revealing information about what others typically do in a given situation in the context of improving disaster risk preparedness associated with climate change. Based on data collected in an online experiment among homeowners in the Netherlands, they examine whether a descriptive norm about the flood insurance purchasing decisions of neighbours influences individuals' insurance choices. They show that the effect of a descriptive norm about the flood insurance penetration rate of neighbours depends positively on the consistency of the norm with prior beliefs and the level of trust homeowners have in insurance agents. They suggest recommendations for policies that aim to improve preparedness against increasing losses related to climate change.

The paper by Arthur Charpentier, Laurence Barry and Molly James looks at the important issue of the trade-off between actuarial fairness and social solidarity in public-private mixed insurance schemes against natural catastrophes. The French scheme reflects such ideas and offers wide coverage for moderate 
premiums to all, but is questioned in its principle by increased exposure to climate risks. Acknowledging that some segmentation may become desirable, the paper examines several models for flood risk and the disparity in premiums they entail.

The paper by Ji Shao assesses empirically the public-private partnership flood insurance system in place in Japan. To that aim, it selects three candidate systems as a way to respond to the widely observed market failure in public-private mixed insurance schemes for natural catastrophe risks. It identifies the market-oriented system as the economically-optimal choice. The methodology is deemed to be suitable for identifying the most adequate public-private partnership system and policymakers are invited to consider its use when implementing their own systems.

The paper by Alejandro Drexler and Richard Rosen investigates empirically the motivations to use reinsurance in the face of catastrophic risks in the U.S. To that aim, they develop a novel approach to measure the use of non-proportional reinsurance and use it to disentangle reinsurance used for catastrophe risk protection from reinsurance used for other motivations, for example regulatory capital relief. Their findings help us to understand how insurers use reinsurance to help cope with the financial burden associated with large natural catastrophe losses.

The paper by Tobias Götze and Marc Gürtler studies insurers' choices of either CAT bonds or reinsurance to determine the situations in which the former are used as substitutes for the latter. The literature suggests that insured risk characteristics and market imperfections may influence the effectiveness and efficiency of reinsurance relative to CAT bonds. CAT bonds may add value to insurers' risk management strategies and may therefore substitute for reinsurance. Using a comprehensive data set comprising U.S. P\&C insurers' financial statements and CAT bond use, the paper shows that insurance companies' choice of risk management instruments is not arbitrary. They find that the added value of CAT bonds mainly stems from nonindemnity bonds and reveal that (non-indemnity) CAT bonds are valuable under high reinsurer default risk, low basis risk and in high-risk layers.

Finally, given the rising popularity of CAT bonds among investors, the paper by Peter Carayannopoulos, Olga Kanj and Fabricio Perez studies the evolution of factors affecting CAT bond pricing for the period 1999-2016. While they find an overall decreasing trend in the price of expected loss risk, large catastrophes increase this price substantially. They find evidence that changes in the price of expected loss risk may be explained by changes in investor effective risk aversion, initiated by catastrophic events triggering CAT bond losses that could bring investors closer to their habit consumption levels and lead to a hard reinsurance market environment.

All in all, we aim to think that this set of papers contributes to the main aim of this journal, which is to improve the scientific knowledge of insurance and to offer a rigorous forum among concerned parties. Governments, businesses, communities, homeowners and individuals all play a key role in managing physical climate risks. These contributions provide some important messages for policymakers and other stakeholders on how best to plan the organisation of natural catastrophe schemes and on the role of insurance mechanisms, whether public or private, as an integral part of climate-related risk management. 


\section{References}

Intergovernmental Panel on Climate Change (IPCC). 2021. Climate Change 2021: The physical science basis. Contribution of Working Group I to the Sixth Assessment Report of the Intergovernmental Panel on Climate Change, ed. V. Masson-Delmotte et al. Cambridge University Press. In Press.

Kousky, C. 2019. The role of natural disaster insurance in recovery and risk reduction. Annual Review of Resource Economics 11 (1): 399-418.

OECD. 2017. OECD Recommendation on disaster risk financing strategies. https://www.oecd.org/daf/ fin/insurance/oecd-recommendation-disaster-risk-financing-strategies.htm.

Task Force of Climate-related Financial Disclosure (TCFD). 2017. Final report: Recommendations of the task force on climate-related financial disclosures and related annexes. https://www.fsb-tcfd.org/ publications/final-recommendations-report/

The Geneva Association. 2018. Climate change and the insurance industry: Taking actions as risk managers and investors. Author: Maryam Golnaraghi. January. https://www.genevaassociation.org/resea rch-topics/extreme-events-and-climate-risk/climate-change-and-insurance-industry-taking-action.

The Geneva Association. 2020. Building flood resilience in a changing climate: Insights from the United States, England and Germany. Authors: Maryam Golnaraghi, Svenja Surminski and Carolyn Kousky. June. https://www.genevaassociation.org/research-topics/building-floodresilience.

Von Peter, G., S. von Dahlen, and S. Saxena. 2012. Unmitigated disasters? New evidence on the macroeconomic cost of natural catastrophes. BIS Working Paper No. 394. Basel: Bank for International Settlements (BIS). http://www.bis.org/publ/work394.pdf.

World Meteorological Organisation (WMO). 2021. State of climate in 2021: Extreme events and major impacts. https://public.wmo.int/en/media/press-release/state-of-climate-2021-extreme-events-andmajor-impacts.

Publisher's Note Springer Nature remains neutral with regard to jurisdictional claims in published maps and institutional affiliations. 